\title{
O papel do enfermeiro no transplante de células tronco hematopoiéticas
}

\author{
The role of nurses in hematopoietic stem cell transplantation \\ El papel de las enfermeras en el trasplante hematopoyético de células madre
}

Tamires de Oliveira Silva Benicá

ORCID: https://orcid.org/0000-0002-6612-2137 Instituto Brasileiro de Medicina de Reabilitação, Brasil E-mail: tamiresbenica@gmail.com

Sany Cristina de Torres Nascimento ORCID: https://orcid.org/0000-0003-0875-4627 Instituto Brasileiro de Medicina de Reabilitação, Brasil E-mail: sanytorres0@gmail.com

Giovana Carbone Pereira

ORCID: https://orcid.org/0000-0003-2774-2613 Instituto Brasileiro de Medicina de Reabilitação, Brasil E-mail: giovanacarbonep@gmail.com

Luciano Godinho Almuinha Ramos

ORCID: https://orcid.org/0000-0001-9958-3151 Instituto Brasileiro de Medicina de Reabilitação, Brasil E-mail:lucianogodinho@yahoo.com.br

\begin{abstract}
Resumo
Este estudo versa sobre o papel do enfermeiro frente ao transplante de células tronco hematopoiéticas. Tem como objetivo destacar a importância do trabalho do enfermeiro no transplante de células tronco hematopoéticas. O presente estudo trata-se de uma revisão integrativa com a seguinte questão norteadora: Qual o papel do enfermeiro, frente ao cuidado do paciente, no transplante de células tronco hematopoiéticas? Para a realização do artigo foi promovida uma revisão integrativa de literatura onde foram selecionadas obras da Biblioteca Virtual de Saúde, BVS Enfermagem Brasil, com os seguintes descritores da base DeCS "Assistência de Enfermagem", "Papel do Enfermeiro" e "Transplante de Células-Tronco Hematopoiéticas" nos idiomas português e inglês entre 2011 e 2020. Como critérios de exclusão: foram descartados os artigos que não se enquadram ao tema proposto, assim como artigos de revisão de literatura. Como critérios de inclusão: foram utilizadas obras publicadas entre os anos de 2011 a 2020 nos idiomas Português e Inglês. O artigo foi subdivido em três categorias que ajudaram a identificar o enfermeiro frente ao transplante de células tronco hematopoiéticas. Foi abordado os conhecimentos necessários para realização do transplante, o enfermeiro frente aos cuidados paliativos e, por fim, o papel do enfermeiro frente a avaliação psicológica dos pacientes durante o transplante de células tronco hematopoiéticas. Concluiu-se que o cuidado exercido pelo enfermeiro é feito de forma integral e o profissional capacitado atua em diversos níveis, desde os mais básicos aos mais complexos e é protagonista no cuidado de pacientes habilitados ao transplante de células tronco hematopoiéticas.
\end{abstract}

Palavras-chave: Assistência de enfermagem; Papel do enfermeiro; Transplante de células-tronco hematopoiéticas.

\begin{abstract}
This study is about the role of nurses in hematopoietic stem cell transplantation. It aims to highlight the importance of nurses' work in hematopoietic stem cell transplantation. It is conceived as an integrative review developed from one guiding question: What is the nurse's role in hematopoietic stem cell transplantation when it comes to patient care? To produce the paper, an integrative literature review was carried out, with papers being selected from the Virtual Health Library, BVS Nursing Brazil, with the following descriptors on the DeCS database "Nursing Assistance", "Nurse's Role" and "Hematopoietic Stem Cell Transplantation" in Portuguese and English between 2011 and 2020. As the exclusion criteria, articles that did not fit the proposed theme, as well as literature review articles, were discarded. As the inclusion criteria: papers published from 2011 to 2020 in Portuguese and English were used. The article was subdivided into three categories that helped to identify nurses facing hematopoietic stem cell transplantation. Such as the knowledge needed to carry out the transplant, the nurse facing palliative care, and finally, nurses' role in the psychological assessment of patients during hematopoietic stem cell transplantation. The paper found that the care provided by nurses is integral and the trained professional works at different levels, from the most basic tasks to the most complex ones, and they are protagonists in the care of patients qualified for hematopoietic stem cell transplantation.
\end{abstract}

Keywords: Nursing care; Nurse's role; Hematopoietic stem cell transplantation. 


\section{Resumen}

Este estudio trata sobre el papel de la enfermera en el trasplante de células madre hematopoyéticas. Su objetivo es resaltar la importancia del trabajo de las enfermeras en el trasplante de células madre hematopoyéticas. Este estudio es una revisión integradora con la siguiente pregunta orientadora: ¿Cuál es el papel de la enfermera, en relación con la atención al paciente, en el trasplante de células madre hematopoyéticas? Para la realización del artículo se realizó una revisión integradora de la literatura, donde se seleccionaron trabajos de la Biblioteca Virtual en Salud, BVS Nursing Brasil, con los siguientes descriptores de la base de datos DeCS “Asistencia de enfermería", "Rol de la enfermera" y "Trasplante de células madres hematopoyéticas" en portugués e inglés entre 2011 y 2020 . Como criterio de exclusión: se descartaron los artículos que no se ajustan a la temática propuesta, así como los artículos de revisión de la literatura. Como criterio de inclusión: se utilizaron trabajos publicados entre los años 2011 a 2020 en portugués e inglés. El artículo se subdividió en tres categorías que ayudaron a identificar a los enfermeros que enfrentan el trasplante de células madre hematopoyéticas. Los conocimientos necesarios para realizar el trasplante, la enfermera que se enfrenta a los cuidados paliativos, y finalmente, el papel de las enfermeras en la evaluación psicológica de los pacientes durante el trasplante de células madre hematopoyéticas. Se concluyó que la atención brindada por enfermeras es integral y el profesional capacitado trabaja en diferentes niveles, desde el más básico hasta el más complejo, y es protagonista en la atención de los pacientes calificados para trasplante de células madre hematopoyéticas.
\end{abstract}

Palabra clave: Atención de enfermería; Rol de la enfermera; Trasplante de células madres hematopoyéticas.

\title{
1. Introdução
}

O transplante de células tronco hematopoiéticas (TCTH) é uma especialidade de tratamento para doenças hematológicas, onco-hematológicas, imunológicas ou hereditárias. O procedimento consiste na infusão endovenosa de células estaminais que possuem o potencial de renovação e origem para outros tipos de células sanguíneas com a finalidade de restaurar a função da medula doente ou lesada e auxiliar no processo imune dos pacientes (INCA, 2018).

Inicialmente, o processo de transplante era usado como medida radicalizada e desesperada em pacientes que não respondiam ao tratamento padronizado contra as disfunções hematológicas, entretanto, com o avanço da tecnologia, aprimorouse o cuidado e o suporte do tratamento. Dessa forma, o transplante passou a ser uma forma de transformação para doenças imunológicas, hematológicas, oncológicas e hereditárias. A compreensão mais ampla do método possibilitou a utilização do procedimento como uma estratégia terapêutica cada vez mais recorrente para tratamento dos distúrbios ocasionados pelo mau funcionamento do sangue e, muitas das vezes, mostra-se como uma única solução para cura de pacientes acometidos, além de manifestar resultados satisfatórios na recuperação do paciente (INCA, 2012).

Desenvolvidas pela medula óssea, as células tronco possuem uma capacidade de autorrenovação e diferenciação em diversas categorias. A estrutura medular é composta por um tecido gelatinoso que preenche o interior dos ossos e possui como principal função o desenvolvimento das células sanguíneas presentes no organismo (RNTC, 2021).

As disfunções atribuídas à medula podem despertar doenças hematológicas, onco-hematológicas, imunológicas e até mesmo hereditárias que podem também ser tratadas com a modalidade terapêutica do transplante, dentre elas: leucemia mieloide aguda, síndromes mielodisplásicas, tumores de células germinativas, amiloidose, anemia aplástica grave e anemia falciforme (Centro de Criogenia Brasil, 2014).

Para que o processo de transplante seja realizado, é necessário a coleta de células tronco. Essas células podem ser encontradas na medula óssea, sangue periférico obtido por meio de aférese - separação de células a partir do sangue recolhido cordão umbilical e placenta após o nascimento de uma criança (Hospital Israelita Albert Einstein, 2021).

Segundo o Registro Nacional de Doadores Voluntários da Medula Óssea (REDOME), há dois tipos de doadores do TCTH compreendidos em: autólogo e alogênico. O transplante autólogo consiste na infusão de células precursoras da medula óssea que são retiradas do próprio paciente transplantado. Essas células são retiradas antes do transplante e passam por um tratamento severo com altas doses de quimioterapia e, às vezes, radioterapia com a finalidade de distinguir células saudáv eis das células doentes (Instituto Oncoguia, 2015). 
No transplante alogênico, o paciente recebe as células tronco que são retiradas de um doador com níveis altos de compatibilidade do material sanguíneo, esse doador pode ser aparentado ou não. A preferência do transplante é sempre da família, todavia, há casos em que o paciente não possui boa compatibilidade com os membros. Então, procura-se os não aparentados compatíveis pelo Registro Nacional de Doadores Voluntários da Medula Óssea (REDOME, 2015).

Algumas literaturas abordam ainda sobre os doadores singênicos. Nesse tipo de transplante, as células são provenientes de um irmão gêmeo idêntico. As fontes de células tronco oriundas do irmão são raras e nem sempre podem ser utilizadas, entretanto, possuem um padrão ideal de compatibilidade (INCA, 2012).

Transplantar células tronco hematopoiéticas é uma intervenção extremamente intensa e pode gerar riscos à vida do paciente, entretanto, o processo de transplante possui uma capacidade potencialmente curativa para diversas espécies de doenças malignas e não malignas (Carvalho, Kaoana de Lima Botto, 2011).

Frente a este procedimento, o enfermeiro está ligado diretamente ao cuidado do paciente, prevenção e deteç̧ão precoce de complicações que o procedimento pode gerar (Gualberto, A., 2012) .

Para promover um cuidado de alta qualidade o profissional necessita ter conhecimento científico para atuar na implementação de planos terapêuticos durante todo o processo de transplante e deve estar em um lugar de liderança na efetivação das atividades privativas do enfermeiro (Tannure, M., \& Gonçalves, A., 2010).

Segundo a Resolução COFEN 358/2009, “...a Sistematização da Assistência de Enfermagem organiza o trabalho profissional quanto ao método, pessoal e instrumentos, tornando possível a operacionalização do processo de Enfermagem." (COFEN, 2009).

O enfermeiro que atua diretamente com o TCTH necessita estar interessado e capacitado para exercer a profissão com afinco, a fim de prestar cuidados de forma sistematizada, desenvolvendo o conhecimento, habilidades e cuidados necessários durante todo o processo de transplante. A Resolução COFEN- 629/2020 assegura que o enfermeiro deve manter suas funções voltadas para o "planejar, executar, coordenar, supervisionar e avaliar os procedimentos hemoterápicos e de Enfermagem nas Unidades, visando assegurar a qualidade do sangue, hemocomponentes e hemoderivados, coletados e infundidos" (COFEN, 2020).

Diante da especialidade do cuidado de enfermagem no transplante de células tronco hematopoiéticas, este trabalho visa destacar a importância do enfermeiro no processo de transplante de células tronco hematopoiéticas.

\section{Metodologia}

Trata-se de uma revisão integrativa de literatura, que objetiva agrupar informações de diversos estudos já realizados sobre o tópico selecionado auxiliando no embasamento teórico do estudo proposto (Whittemore, \& Knafl, 2005).

Após a definição da questão norteadora "Qual o papel do enfermeiro, frente ao cuidado do paciente, no transplante de células tronco hematopoiéticas?", a base de dados BVS Enfermagem Brasil foi utilizada como fonte de pesquisa com auxílio dos descritores da base DeCS "Assistência de Enfermagem", "Papel do Enfermeiro" e "Transplante de Células-Tronco Hematopoiéticas".

Como critérios de inclusão foram utilizados: artigos selecionados que abordassem a atuação do enfermeiro no processo de transplante de células-tronco hematopoiéticas, publicados nos últimos entre os anos 2011 e 2020, nos idiomas português e inglês. Foram descartados os artigos que não se enquadram ao tema proposto, assim como artigos de revisão de literatura.

Ao realizar a busca na base selecionada, os descritores combinados ao período e idiomas selecionados trouxeram 12 resultados. Após a leitura dos títulos e resumos, dos 12 resultados, 4 não atendiam ao tema proposto, portanto, foram descartados e uma obra consistia em uma tese de mestrado que originou 1 dos artigos selecionados ao final do processo, sendo assim, foi 
selecionada para embasamento teórico. Os 7 artigos restantes, passaram por um processo de leitura na íntegra onde obtiveram aprovação para compor a amostra deste estudo.

Os artigos selecionados passaram pelo processo de leitura e construção de resenha crítica individual para coleta de dados pertinentes, desta forma, permitindo a visualização de suas principais características e identificação dos artigos relacionados ao tema.

Figura 1: Fluxograma de busca e seleção de artigos. Rio de Janeiro, RJ, Brasil, 2020.

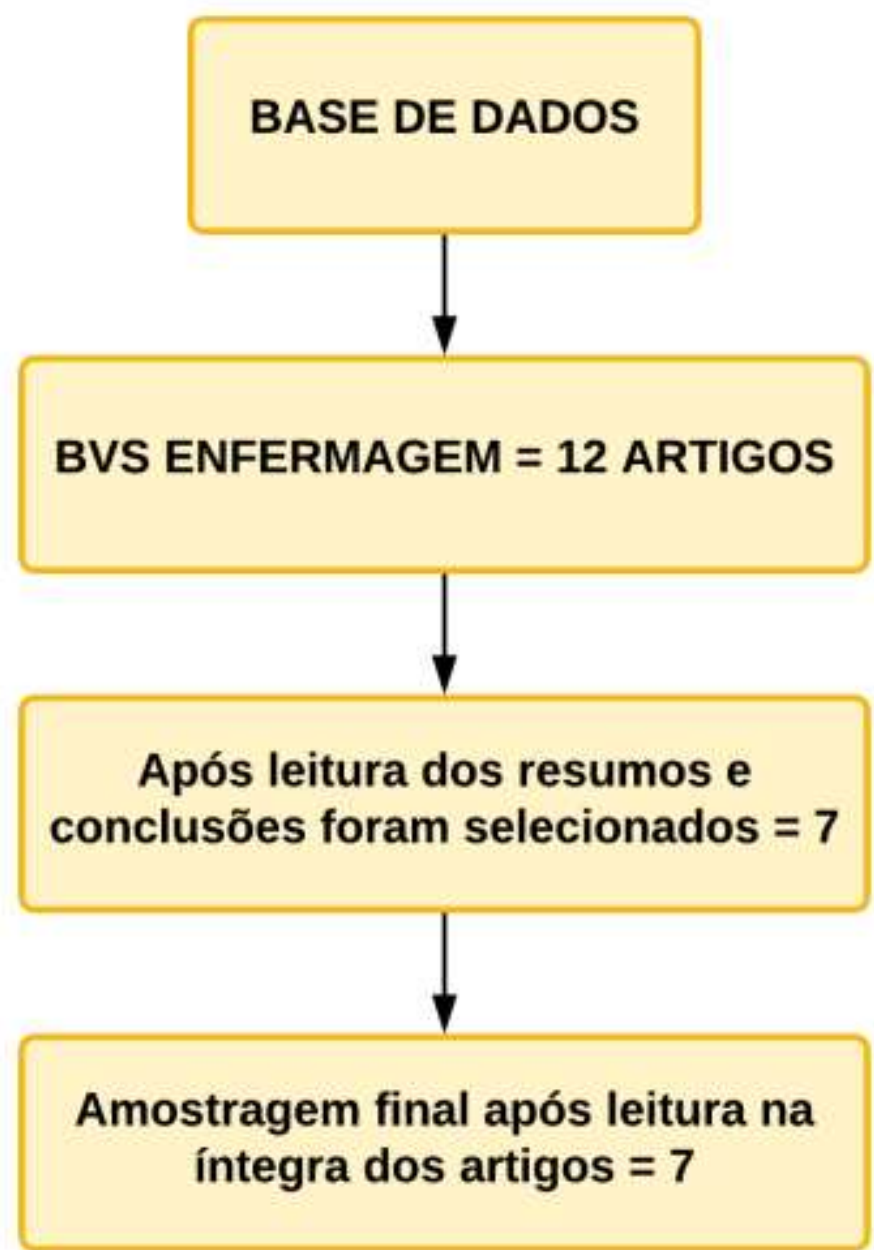

Fonte: Autores.

O fluxograma acima relata as etapas realizadas para a seleção dos artigos deste estudo. Inicialmente, foi encontrado um universo de 12 artigos na base utilizada, após a análise dos resumos e conclusões sobraram 7 artigos que se enquadram no tema abordado. Após leitura na íntegra, os 7 artigos se mantiveram na apresentação final deste estudo.

\section{Resultados e Discussão}

Os critérios utilizados para inclusão de artigos na revisão foram: artigos selecionados que abordassem a atuação do enfermeiro no processo de transplante de células-tronco hematopoiéticas, publicados nos últimos entre os anos 2011 e 2020, nos idiomas português e inglês. O Quadro 1 demonstra a divisão dos artigos que foram selecionados para a composição do estudo. 
Quadro 1. Artigos selecionados para o estudo. Rio de Janeiro, RJ, Brasil, 2021.

\begin{tabular}{|c|c|c|}
\hline AUTOR/ANO & TÍTULO & OBJETIVO \\
\hline Crooks. et al/2013 & $\begin{array}{l}\text { Monitoring patient distress and related } \\
\text { problems before and after hematopoietic stem } \\
\text { cell transplantation. }\end{array}$ & $\begin{array}{l}\text { Monitorar pacientes aptos a realizarem o transplante horas } \\
\text { após os mesmos se qualificarem; estruturar a coordenação da } \\
\text { equipe multidisciplinar para ajudar a aliviar a angústia dos } \\
\text { pacientes e reduzir os problemas ao longo do tempo da } \\
\text { qualificação de três a seis meses após o procedimento. }\end{array}$ \\
\hline $\begin{array}{l}\text { Lima \& } \\
\text { Bernardino/2014 }\end{array}$ & $\begin{array}{l}\text { 1. O cuidado de enfermagem em } \\
\text { unidade de transplante de células-tronco } \\
\text { hematopoiéticas }\end{array}$ & $\begin{array}{l}\text { Identificar atividades de cuidado dos enfermeiros de uma } \\
\text { unidade de transplante classificadas segundo o referencial } \\
\text { canadense. }\end{array}$ \\
\hline $\begin{array}{l}\text { Harden \&. } \\
\text { Schembri/2014 }\end{array}$ & $\begin{array}{l}\text { Early Intervention With Transplantation } \\
\text { Recipients to Improve Access to and } \\
\text { Knowledge of Palliative Care. }\end{array}$ & $\begin{array}{l}\text { Melhorar a qualidade de vida iniciando antecipadamente os } \\
\text { cuidados paliativos em pacientes submetidos ao processo de } \\
\text { transplante de medula óssea e aperfeiçoar o acesso a esses } \\
\text { cuidados e os conhecimentos antes mesmo da admissão do } \\
\text { paciente no transplante e aprimorar o acesso a esses cuidados } \\
\text { e os conhecimentos antes mesmo da admissão do paciente no } \\
\text { transplante. }\end{array}$ \\
\hline Thomson. et al/2014 & $\begin{array}{l}\text { Transitions of Care A Hematopoietic Stem } \\
\text { Cell Transplantation Nursing Education } \\
\text { Project Across the Trajectory. }\end{array}$ & $\begin{array}{l}\text { Fornecer uma abordagem sistemática útil visando à } \\
\text { padronização dos métodos de ensino do paciente em várias } \\
\text { funções profissionais de enfermagem durante a trajetória do } \\
\text { mesmo no transplante de células hematopoiéticas, integrar os } \\
\text { cuidados paliativos na gestão integral dos receptores e famílias } \\
\text { do paciente submetido ao transplante de células tronco } \\
\text { hematopoiéticas e discutir os efeitos colaterais e a toxicidade } \\
\text { observados dos regimes de alta dose de condicionamento e os } \\
\text { resultados do TCTH. }\end{array}$ \\
\hline Tierney. et al/2014 & $\begin{array}{l}\text { Palliative care of hematopoietic cell transplant } \\
\text { recipients and families. }\end{array}$ & $\begin{array}{l}\text { Fornecer apoio para a integração precoce dos cuidados } \\
\text { paliativos no tratamento dos receptores e famílias de } \\
\text { transplante de células tronco hematopoiéticas (TCTH). }\end{array}$ \\
\hline Huang. et al//2014 & $\begin{array}{l}\text { Experience of nurses caring for child with } \\
\text { hematopoietic stem cell transplantation in } \\
\text { general pediatric ward: a descriptive } \\
\text { phenomenological approach. }\end{array}$ & $\begin{array}{l}\text { Explorar a vivência dos enfermeiros cuidando de crianças } \\
\text { submetidas ao TCTH e isoladas numa ala pediátrica. }\end{array}$ \\
\hline Sabo./2011 & $\begin{array}{l}\text { Compassionate presence: The meaning of } \\
\text { hematopoietic stem cell transplant nursing. }\end{array}$ & $\begin{array}{l}\text { Compreender os efeitos do trabalho de enfermagem sobre a } \\
\text { saúde psicossocial e o bem-estar dos enfermeiros do TCTH. }\end{array}$ \\
\hline
\end{tabular}

Fonte: Autores.

O Quadro 1 traz os artigos selecionados para este artigo separados em autor e ano, título e objetivo do estudo para uma visualização mais compreensível e detalhada.

\subsection{Transplante de células tronco: conhecimentos necessários para realização desta atividade}

$\mathrm{O}$ transplante de células tronco hematopoiéticas (TCTH) equivale a uma modalidade de tratamento vista como um procedimento altamente invasivo e de alta complexidade, que envolve o uso de medicações quimioterápicas, sessões de radioterapia, hemotransfusões e outros métodos que podem ocasionar em inúmeros riscos a vida do paciente (Thomson $\mathrm{B}$ et al, 2015).

No entanto, em muitos casos, mostra-se como uma única solução para pacientes com doenças hematológicas, oncológicas, hereditárias e imunológicas (Lima, \& Bernardino, 2014). 
Considerando que as doenças que acometem as funções hematológicas e a espécie de recurso terapêutico utilizado são extremamente agressivas, o paciente que é submetido ao processo transplante necessita de cuidados específicos e contínuos para recuperação do comprometimento orgânico decorrentes do tratamento. (Lima, K., \& Bernardino, E. 2014).

A presença de enfermeiros capacitados e com conhecimentos específicos científicos que auxiliem efetivamente na elaboração de planos terapêuticos totalmente detalhados é de suma importância no processo de transplante, na recuperação e prevenção de complicações que podem manifestar-se no período de reabilitação do paciente (Lima, K. \& Bernardino, E. 2014).

Wanda Horta (1970) define a enfermagem como a ciência e a arte de assistir o paciente de forma a torná-lo independente, atuando na educação, recuperação e manutenção da sua saúde. O estudo evidencia o profissional de enfermagem como um dos principais protagonistas na realização no cuidado de pacientes transplantados.

Uma assistência prestada de forma eficaz pelo profissional capacitado permite que as necessidades de caráter físico, educacional e psicossocial sejam supridas de forma que ocasione em resultados positivos na recuperação do paciente. (Huang, et al, 2014)

A relação enfermeiro-paciente permite que os profissionais de saúde estejam relacionados diretamente aos pacientes e à família, atuando de forma crucial na elaboração de estratégias, na forma gerencial e assistencial (Lima, \& Bernardino, 2014).

De acordo com a Resolução 629/2020, do COFEN, dispõe sobre as competências do enfermeiro em hemoterapia na coleta, armazenamento, prescrição dos cuidados de enfermagem, controle de qualidade, assistência a doadores e pacientes, além de outras atividades, anexas à resolução.

O enfermeiro assistencial executa suas atividades voltadas ao ambiente, à proteção do paciente, verificação e acompanhamento de dados do paciente, cuidados relacionados ao procedimento, execução da sistematização da assistência de enfermagem, atendimento a solicitação dos pacientes, cuidados com a terapia intravenosa, cuidados com a terapia medicamentosa, entre outros (Lima, \& Bernardino, 2014).

Já, o enfermeiro gerencial atua na coordenação e na liderança de suas equipes, monitorando o processo de trabalho para o cumprimento das técnicas, influenciando diretamente sobre a assistência prestada ao paciente, interferindo no cuidado, no tempo de hospitalização, na redução de custos e contribuindo diretamente para a satisfação do paciente e da família (COFEN, 2018).

Subdividido em duas categorias, o processo gerencial no transplante abrange os cuidados técnicos gerais e os cuidados técnicos específicos. Os cuidados técnicos gerais estão correlacionados à proteção do paciente, incluindo o armazenamento dos pertences pessoais, paramentação e uniformização da instituição, além da higienização das mãos como parte do protocolo geral (Lima, \& Bernardino, 2014).

Por outro lado, cuidados técnicos específicos abrangem o recebimento das bolsas de sangue do cordão umbilical congelado para o transplante, cuidados com o armazenamento das bolsas, além de requisição de células mesenquimais a outras instituições para tratamento de doença de enxerto contra o hospedeiro (Lima, \& Bernardino, 2014).

Dispõe ainda ao gerenciamento a supervisão do ensinar, a orientação e a observação de pontos positivos e negativos do serviço prestado. O enfermeiro gerencial fica responsável pela organização e distribuição de acordo com as necessidades do cliente e de cada membro da equipe, adequando assim de forma precisa a qualidade da assistência da enfermagem (COFEN, 2018).

A sistematização da assistência de enfermagem deve ocorrer em todas as fases do transplante, ainda mais por se tratar de uma atividade privativa do enfermeiro (Lima, \& Bernardino, 2014). A orientação e supervisão da equipe de enfermagem bem como o registro de todas as informações obtidas pelo processo de enfermagem são essenciais para um cuidado eficaz, de forma a torná-lo mais científico baseado na condição clínica individual do paciente e menos intuitivo (Tannure, \& Gonçalves, 2010). 
O processo de enfermagem é um método científico que favorece a prestação do cuidado de modo organizado. Consiste em realizar o cuidado em etapas que devem ser previamente estabelecidas, tais como, coleta de dados, diagnóstico, planejamento, implementação dos cuidados de enfermagem e avaliação dos resultados obtidos (Tannure, \& Gonçalves, 2010).

Por fim, foi visto que na unidade de transplante o enfermeiro capacitado desempenha um papel importante no cuidado dos pacientes acometidos, atuando tanto nos níveis mais básicos quanto nos mais complexos, favorecendo uma melhora na qualidade de vida dos pacientes e dos acompanhantes.

\subsection{Cuidados paliativos: uma realidade presente no processo de transplante}

Os cuidados paliativos consistem em ações que são realizadas com intuito de melhorar a qualidade de vida. $\mathrm{O}$ alívio de sintomas de doenças que comprometem o estado físico, psicossocial e espiritual também estão inclusos nesses cuidados (Harden, \& Josette A. Schembri 2016). De acordo com a Sociedade Brasileira de Oncologia e com a Sociedade Americana de Oncologia Clínica, os cuidados paliativos devem ser praticados desde o diagnóstico da doença e durante todo o processo do tratamento (Harden, \& Josette A. Schembri 2016).

Alguns autores defendem que os cuidados paliativos conferem em cuidados interdisciplinares especializados para pacientes com doenças graves e possuem como objetivo minimizar os sintomas e angústias (Tierney, 2014).

Segundo a Organização Mundial da Saúde (OMS), os cuidados paliativos consistem na assistência promovida por uma equipe multidisciplinar, que objetiva a melhoria da qualidade de vida do paciente e seus familiares, diante de uma doença que ameace a vida, por meio da prevenção e alívio do sofrimento, por meio de identificação precoce, avaliação impecável e tratamento de dor e demais sintomas físicos, sociais, psicológicos e espirituais.

Através da implementação precoce e da orientação sobre a importância dos cuidados paliativos, a aceitação do tratamento pelo paciente, a qualidade de vida, humor e sobrevida melhoram significativamente (Harden, \& Josette Schembri 2016).

Considerando os sintomas físicos, emocionais e psicológicos que o paciente acumula durante todo o processo da doença, faz-se necessário a adoção precoce da conduta terapêutica, respeitando os limites do próprio paciente, visando à melhora dos sintomas e o empoderamento mental. (INCA, 2021)

O profissional de enfermagem deve liderar os cuidados paliativos e estar à frente na educação dos pacientes e de suas famílias. O enfermeiro possui um papel importante na identificação das necessidades e conhecimento de cada paciente, desta forma executam de forma integral todos os cuidados voltados para a manutenção da vida. (Harden, \& Josette A. Schembri 2016).

Tal processo permite que os enfermeiros mantenham suas ações voltadas principalmente na prevenção de infecções, além disso, ele também exerce um papel fundamental no alívio da dor em pacientes que desenvolvem mucosite, inflamação na parte interna da boca e na garganta que pode ocasionar em úlceras (Tierney, 2014).

Complementar a isso, é relatado também que os cuidados estão diretamente ligados à melhoria na qualidade de vida, como a diminuição dos sintomas, manutenção do humor e, consequentemente, diminuição da carga dos prestadores de cuidados (Tierney, 2014).

De acordo com o Manual de Cuidados Paliativos da Academia Nacional de Cuidados Paliativos, o enfermeiro tem como responsabilidades avaliar sistematicamente os sinais e sintomas do paciente, auxiliar a equipe multidisciplinar conforme a prioridade do cliente, reforçar as orientações clínicas e inserção da família no âmbito dos cuidados. É de extrema importância que os profissionais sejam capacitados, visto que, ele é o elo entre sua equipe, seus pacientes e a família dos mesmos. 
Por fim, entende-se que os cuidados paliativos compreendem um cuidado sensível e um processo de educação, visto que, as ações praticadas pelos profissionais exigem uma proximidade física e afetiva. A comunicação entre o enfermeiro-paciente deve ser clara e as orientações devem ser feitas de forma que se concretizem na prática, gerando confiança para ambos os lados.

\subsection{Acometimento psicológico: o papel do enfermeiro na avaliação psicológica}

A modalidade terapêutica do transplante de células tronco hematopoiéticas é vista muitas vezes como uma única solução para pacientes com doenças comprometedoras do sistema hematológico (Lima, \& Bernardino, 2014).

Entretanto, alguns fatores psicológicos provocados por sofrimentos psíquicos ao decorrer do processo influenciam de forma significativa no tratamento e são agravantes em potencial para resultados indesejáveis. Podendo ser até mais desafiadoras do que as questões médicas tratadas durante o próprio processo de transplante, portanto, tratar o paciente e a família como centro da pesquisa e do cuidado possibilita uma diminuição nas taxas de morbidades psicossociais. (Crooks, et al, 2013)

O diagnóstico de doenças que podem gerar comprometimento orgânico grave possui a capacidade de provocar um sofrimento psíquico no paciente, contribuindo para a não adesão e má adesão do tratamento de forma efetiva (Sabo, 2011).

Segundo o Caderno de Atenção Básica - Saúde Mental 2013, fatores marcantes na vida de uma pessoa podem provocar sofrimento psicológico, fatores esses que podem ser desencadeados por sentimentos de impotência perante uma condição clínica preocupante. Pacientes de TCTH, caracteristicamente, já sofrem com a pressão psicológica em torno da doença que os levou até o procedimento em questão.

O paciente ansioso dificulta o acesso à informação e, em muitos casos, a família não compreende e não sabe como auxiliar nas questões emocionais. O empoderamento e a orientação quanto ao assunto facilitam a comunicação entre o paciente e o profissional de saúde. (Thomson et al, 2015).

Pacientes habilitados para realizar o transplante muitas vezes não possuem a certeza ou não percebem a necessidade do método terapêutico devido à falta de conhecimento acerca do tema. A ausência de uma orientação bem prestada sobre a modalidade terapêutica de transplante e todas as suas fases, pode ocasionar em medo, ansiedade e falta de confiança do para com a equipe multidisciplinar (Harden, \& Josette A. Schembri 2016). É imprescindível que os pacientes aptos ao transplante sejam bem orientados sobre todo o processo para que ele reconheça a importância e a necessidade do cuidado.

De acordo com a Política Nacional da Saúde Mental, afirma-se que é de direito do paciente receber o maior número de informações a respeito tanto da sua doença quanto de seu tratamento. Isto é, um paciente plenamente orientado sobre todo o processo facilita sua adesão ao tratamento e entendimento do mesmo, assim, contribuindo para a comunicação efetiva entre família, paciente e profissional.

O enfermeiro desempenha um papel extremamente importante na orientação e qualidade de vida dos enfermos (Harden, \& Josette A. Schembri 2016).

Cuidar permitiu que uma conexão entre os enfermeiros, pacientes e familiares fosse iniciada abrindo espaço para uma melhor assistência, portanto, quando essa conexão não é alcançada, os enfermeiros vêem seu trabalho se tornar pouco eficaz - o que não representa o propósito da profissão (Sabo, 2011).

Compreender o sofrimento, tornou-se um processo natural na relação enfermeiro-paciente. O profissional que consegue se conectar firmemente com o paciente, abre oportunidade para que haja uma comunicação efetiva e um melhor posicionamento entre ambas as partes favorecendo o sentimento de esperança (Sabo, 2011).

A Resolução COFEN Nº 0599/2018 dispõe sobre as competências do enfermeiro no campo da saúde mental. Dentre as competências podemos ressaltar o estabelecimento de um relacionamento terapêutico onde o profissional cuida do atendimento 
das necessidades, participa de ações de psicoeducação e promoção de vínculo terapêutico, escuta atenta e compreensão empática no âmbito de atividades da enfermagem aos pacientes e seus familiares.

\section{Conclusão}

Enfermeiros são figuras indispensáveis e essenciais durante todo o processo de transplante, visto que são os profissionais que estabelecem uma relação mais extensa e dedicam grande parte do seu tempo ao longo do tratamento aos enfermos. É necessário que estejam totalmente aptos e capacitados cientificamente para exercer a prática do cuidado, garantindo uma assistência efetiva ao paciente e seus familiares.

A ausência do conhecimento acerca desta atividade, gera insegurança e ocasiona um déficit na orientação que deveria ser bem realizada. A desconfiança por parte do paciente se faz presente e nesses casos pode influenciar diretamente e de forma significativa na qualidade da assistência, podendo provocar uma piora no quadro clínico e gerar possíveis frustrações para a família.

Manter a sistematização da assistência da enfermagem e uma orientação de qualidade é de suma importância para evitar resultados inesperados e indesejáveis durante e após o transplante.

É necessário que o enfermeiro tenha suas ações voltadas às questões biológicas, sociais, espirituais e psicológicas do paciente, sempre utilizando com atenção os diagnósticos de enfermagem, de acordo com as necessidades apresentadas pelo indivíduo e família, exercendo o cuidado de forma que essas necessidades sejam supridas e seu estar físico, espiritual, mental e social seja restaurado.

Constatou-se que o enfermeiro frente ao transplante atua de forma integral e é protagonista no cuidado de pacientes habilitados ao transplante.

O cuidado que este profissional possui varia em níveis mais básicos, desde a implementação do processo de enfermagem, cuidados durante toda esta etapa, realização de cuidados paliativos até a recuperação pós transplante, favorecendo uma melhora na qualidade de vida dos pacientes e acompanhantes.

No entanto, o conhecimento identificado neste estudo sobre o papel do enfermeiro frente ao transplante de células tronco hematopoiéticas, nas publicações, mostrou-se reduzido. Todavia, entre os artigos pesquisados, a importância do enfermeiro nesta atividade demonstrou que a qualidade assistencial prestada é fundamental e faz a diferença nesta prática prestada.

Pretendeu-se com este estudo contribuir para o conhecimento acerca do papel do enfermeiro frente ao transplante, possibilitando a realização de novas pesquisas científicas, cursos de aprimoramento e capacitação, propiciando uma melhora na performance do enfermeiro na área.

\section{Referências}

Carvalho, K. de L. B. (2011). Funções e contribuições do enfermeiro em transplante de células-tronco hematopoéticas. AcervoDigital da UFPR. https://acervodigital.ufpr.br/handle/1884/27321

Centro de Criogenia Brasil (2014). Célula-Tronco Hematopoiética (CTH). https://ccb.med.br/texto/celula-tronco-hematopoietica

Crooks, M., Seropian, S., Bai, M., \& McCorkle, R. (2013). Monitoring patient distress and related problems before and after hematopoietic stem cell transplantation. Palliative and Supportive Care, 12(1), 53-61. 10.1017/S1478951513000552

Gualberto, A. (2012). Transplante de Células Tronco Hematopoiéticas. http://bvsms.saude.gov.br/bvs/publicacoes/inca/Ana_Gualberto _transplante_celulas_tronco.pdf

Harden, K. \& Josette A. Schembri (2016). Early Intervention With Transplantation Recipients to Improve Access to and Knowledge of Palliative Care. Clinical Journal of Oncology Nursing, 20(4), E88-E92. 10.1188/16.CJON.E88-E92 
Hospital Israelita Albert Einstein (2021). Transplante de células-tronco hematopoiéticas (TCTH). https://www.einstein.br/especialidades/hematologia/examestratamentos/tmo\#: :text=O\%20transplante\%20de\%20c\%C3\%A9lulas-tronco\%20hematopoi\%C3\%A9ticas\%20consi ste\%2C\%20porta nto \%2C\%2 0em,d e\%20c \%C3\%A9lulas\%20do\%20cord\%C3\%A3o\%20umbilical

Huang, Y.-P., Kellett, U., Wang, S.-Y., Chang, M.-Y., \& Chih, H.-M. (2014). Experience of Nurses Caring for Child With Hematopoietic Stem Cell Transplantation in General Pediatric Ward: A Descriptive Phenomenological Approach. Cancer Nursing, An International Journal for Cancer Care Research 37(5), E32-E39. doi: 10.1097/NCC.0000000000000097

Instituto Nacional de Câncer José Alencar Gomes da Silva (INCA) (2012). Tópicos em transplante de células-tronco hematopoéticas. http://bvsms.saude.gov.br/bvs/publicacoes/topicos_transplante_celtronco_hematopoeticas.pdf

Instituto Nacional de Câncer José Alencar Gomes da Silva (INCA) (2018). Transplante de medula óssea. https://www.inca.gov.br/tratamento/transplante-demedula-ossea

Instituto Nacional de Câncer José Alencar Gomes da Silva (INCA) (2021). Cuidados Paliativos. https://www.inca.gov.br/controle-do-cancer-do-colo-doutero/acoes-de-controle/cuidados-paliativos

Instituto Oncoguia (2015). Transplante de Células Tronco para Mieloma Múltiplo: http://www.oncoguia.org.br/conteudo/transplante-de-celulas-tronco-paramieloma-multiplo/2009/397/

LEI N. 10.216, DE 6 DE ABRIL DE 2001. Política Nacional Da Saúde Mental. (n.d.). http://cgj.tjrj.jus.br/documents/1017893/1038413/politica-nac-saudemental.pdf

Lima, K., \& Bernardino, E. (2014). O cuidado de enfermagem em unidade de transplante de células-tronco hematopoéticas. Texto \& Contexto - Enfermagem, 23(4), 845-853. doi: 10.1590/0104-07072014000440013

Parecer de Câmara Técnica Nº2/2018/CTLN/COFEN. (2018). COFEN - Conselho Federal de Enfermagem. http://www.cofen.gov.br/parecer-n-02-2018cofen-ctln_61504.html

Registro Nacional de Doadores de Medula - REDOME (2015). Para quais Indicações se Utiliza o Transplante | Óssea. http://redome.inca.gov.br/medulaossea/para-quais-indicacoes-se-utiliza-o-transplante/

Resolução COFEN No 0599/2018 (2018. COFEN - Conselho Federal de Enfermagem. http://www.cofen.gov.br/wp-content/uploads/2018/12/Re solu\%C3\%A7\%C3\%A3o-599-2018-ANEXO-APROVA-NORMA-PARA-ATUA\%C3\%87\%C3\%83O-DA-EQUIPE-DE-ENFERMAGEM-EM-

SA\%C3\%9ADE-MENTAL-E-PSIQUIATRIA-ARQUIVO-EM-PDF.pdf

Resolução COFEN No 358/2009 (2009). COFEN - Conselho Federal de Enfermagem. http://www.cofen.gov.br/resoluo-cofen-3582009_4384.html

Resolução COFEN No 629/2020. (2020). COFEN - Conselho Federal de Enfermagem. http://www.cofen.gov.br/resolucao-cofen-no-629-2020_77883.html

Rede Nacional de Terapia Celular - RNTC (2021). O que são células-tronco?. http://www.rntc.org.br/ceacutelulastronco.html\#: :text=S\%C3\%A3o\%20tr\%C3\%AAs\%20os\%20principais\%20tipos,cientistas\%20em\%20laborat\%C3\%B3rio\%20em\%202007.

Sabo, B. M. (2011). Compassionate presence: The meaning of hematopoietic stem cell transplant nursing. European Journal of Oncology Nursing, 15(2), 103111. doi: $10.1016 /$ j.ejon.2010.06.006

Tannure, M., \& Gonçalves, A. (2010). SAE Sistematização da Assistência de Enfermagem: Guia Prático (2nd ed.). Guanabara Koogan.

Thomson, B., Gorospe, G., Cooke, L., Giesie, P., \& Johnson, S. (2015). Transitions of Care: A Hematopoietic Stem Cell Transplantation Nursing Education Project Across the Trajectory. Clinical Journal of Oncology Nursing, 19(4), E74-E79. 10.1188/15.cjon.e74-e79

Tierney, D. K., Passaglia, J., \& Jenkins, P. (2014). Palliative Care of Hematopoietic Cell Transplant Recipients and Families. Seminars in Oncology Nursing, 30(4), 253-261. 10.1016/j.soncn.2014.08.007

Whittemore, R., \& Knafl, K. (2005). The integrative review: updated methodology. Journal of advanced nursing, 52(5), 546-553. 10.1111/j.13652648.2005.03621.x

World Health Organization. (2020). National cancer control programmes: policies and managerial guidelines. Who.int. https://apps.who.int/iris/handle/10665/42494 